\title{
Dossier « Le champ des commons en question : perspectives croisées » European mixed fisheries as a complex commons
}

\author{
Douglas Clyde Kongshøj Wilson
}

Professor MSO in Fisheries Sociology, Innovative Fisheries Management - An Aalborg University Research Centre, Department of Development and Planning, 9000 Aalborg, Denmark

\section{Keywords:}

common fisheries

policy;

fisheries management; ecosystem approach; commons; mixed fisheries

\section{Mots-clés :}

politique commune de la pêche ; gestion des pêches ; démarche écosystémique ; biens communs ; pêcheries mixtes

\begin{abstract}
The European Union has declared its intention to move in the direction of an ecosystem approach to fisheries management. Their experience with the management of multi-species, mixed fisheries (MSMF) is one area where insight can be gained about what this may mean in practice. The present paper draws on extensive discussions with stakeholders and the observation of a number of fisheries management related meetings to outline the main challenges that MSMF management has presented. It concludes that an ecosystem approach will lead to more situations where it will be difficult to carry out direct technical regulation, to assign individual property rights or even to effectively divide the resources into distinct units. Hence, common property institutions will become more, rather than less, relevant as management approaches in developed country fisheries evolve.
\end{abstract}

Résumé - Les pêcheries mixtes européennes, un bien commun complexe ? L'Union européenne a signifié son intention d'évoluer vers une approche par écosystèmes de la gestion des pêches. Son expérience en matière de gestion des pêches mixtes et multi-espèces (Management of Multi-species, Mixed Fisheries, MSMF) constitue un domaine permettant d'éclairer les implications possibles de cette approche dans la pratique. L'article se base sur de nombreuses discussions avec les acteurs impliqués ainsi que sur l'observation de réunions sur la gestion des pêches pour faire apparaître les principaux défis auxquels s'est affrontée la gestion MSMF. Il conclut que l'approche par écosystèmes induirait des situations plus nombreuses encore où il serait plus difficile de mettre en œuvre des régulations techniques directes, d'attribuer des droits de propriété individuels ou même de diviser efficacement les ressources en unités distinctes. De ce fait, les institutions en termes de gestion de biens communs vont devenir d'autant plus pertinentes à mesure qu'évoluent les façons d'aborder la gestion des pêches dans les pays développés.

\section{Introduction: the emergence of a new complex commons}

This paper explores the relevance of commons theory for understanding policy dilemmas in a quickly evolving, industrialised social-ecological system (SES): multi-species, mixed fisheries in Europe. Social scientists tend to see fisheries as commons, i.e. as subtractable, common pool resources that, when access to their exploitation is open, are subject to the tragedy of the commons. The two broad responses these social scientists suggest are attempts at "enclosure" (Hannesson, 2004) or establishing institutions for sharing the resource as common property ${ }^{1}$
(Ostrom, 1990; McCay and Acheson, 1987). Both approaches involve the empowerment of the commoners, meaning the users or those otherwise concerned with the resource, to manage the commons. However, where one person sees a SES as filled with commons dilemmas, another may see this as a relatively minor aspect. In European fisheries, managers view their work much more often as the technical regulation of an industry rather than as dealing with a commons. This regulatory model is in natural tension with the commons model. Government

\footnotetext{
1 An excellent gateway to the literature on such institutions is the International Association for the Study of Commons (www.iasc-commons.org).
}

Corresponding author: dw@ifm.aau.dk 
regulators of industries do not prioritise the empowering of those they seek to regulate; for one thing in SES such as fisheries where multiple stakeholders are often in conflict, they are very concerned with avoiding perceptions of regulatory capture by a subset of stakeholders (e.g. Froese, 2011).

Commons are not found in nature. They are social constructs rooted in malleable forms of rights to resources. We sometimes radically recreate commons in response to shifts in ecological realities, incentive structures, discourses and institutional imperatives. For the last generation the European Union (EU), through its Common Fisheries Policy (CFP), has constructed European fisheries as a large set of simple commons: individual stocks of commercially important fish. Now, with the new Marine Strategy Framework Directive, the EU is in effect inverting this construction by creating a small set of complex commons through the adoption of an ecosystem approach to fisheries management (EAFM) within a broader marine management strategy that includes all other recreational and commercial uses of the sea (CEC, 2008, CEC, 2009). These new commons will resemble multiple-use, regional sea areas shared by several Member States and criss-crossed by multi-scale action arenas. By "complex commons" I mean commons that involved several common pool resources and public goods provision problems that must be addressed simultaneously at multiple scales.

The move to an EAFM is a policy goal and has not yet begun to take on an operational form. We can, however, empirically examine its implications by looking at analogous efforts that in some ways are a first step toward an EAFM: the recovery of depleted fish stocks within multispecies, mixed fisheries (MSMF). These are fisheries where more than one species are present in the area being fished and where more than one fishery is operating. Just as an EAFM must deal with multiple species, habitats and user groups, in MSMF interactions exist both among fish species, i.e. as predators or prey, and among fisheries catching targeted species, potentially valuable by-product species, and by-catch of undersized fish or protected species. Different kinds of fishing pursuing different kinds of fish in the same space present only one subset of the considerations required by an EAFM. However, it is one of the largest single subsets of EAFM issues and the institutions required have similarly complex and interdependent objectives.

The paper's basic argument is that as an SES becomes more complex, commons theory becomes more useful for guiding the creation of institutions for sustainable use of environmental services. Furthermore, increasing complexity also leads to common property approaches becoming more relevant because enclosure approaches are more likely to fail in practice. This argument is an important addition to our understanding of commons.
Nearly all empirical examples through which commons theory has been developed, e.g. those collected by the Workshop in Political Theory and Policy Analysis at Indiana University (Ostrom, 1990), have been found in much simpler SESs than the highly developed European seafood industry. This is true even in developed countries where terrestrial common property regimes are usually found in marginal areas and may be viewed, often erroneously (Short, 2008) as fading anachronisms. The MSMF experience suggests, for marine SESs, first that great complexity undermines the effectiveness of natural resource management based on the pronouncement and enforcement of technical rules. Second, great complexity also undermines the clear division of the resource needed for effective enclosure.

This argument is illustrated as follows. The second and third sections of the paper provide the reader with background material on European fisheries management and the EAFM respectively. The fourth section presents stakeholder views of MSMF recovery plans. There is little that can illuminate both the ecological and institutional issues involved in a complex SES as well as multiple conversations with and observations of scientists, managers and other stakeholders. In this case this means twentyfour individual interviews and four focus group interviews with scientists, managers, Regional Advisory Council leaders, fishers and members of environmental NGOs (ENGO) and the observation of fifteen fisheries management meetings. While this field work cannot claim to be statistically representative of the stakeholders involved, it does include representatives of the most active groups and reflects their respective opinions on the issues considered in the paper. In the fourth section, stakeholder views of the overall problem of MSMF management are examined and three specific areas are described in which recovery plans in MSMF face problems of legitimacy. The final section summarises the argument.

\section{A brief description of EU management institutions}

The purpose of this section is to allow the reader to understand the relationships between the institutions mentioned in the remainder of the paper. European fisheries are managed through the Common Fisheries Policy (CFP), which is one of the few policy arenas for which the Member States have ceded decision-making power to the EU with final decisions made by the Council of Ministers. The European Commission admits that the CFP has failed to sustain fish stocks, pointing out that $88 \%$ of EU stocks are being fished beyond agreed targets, and $30 \%$ of these stocks are so depleted they may not be able to replenish (CEC, 2009). 


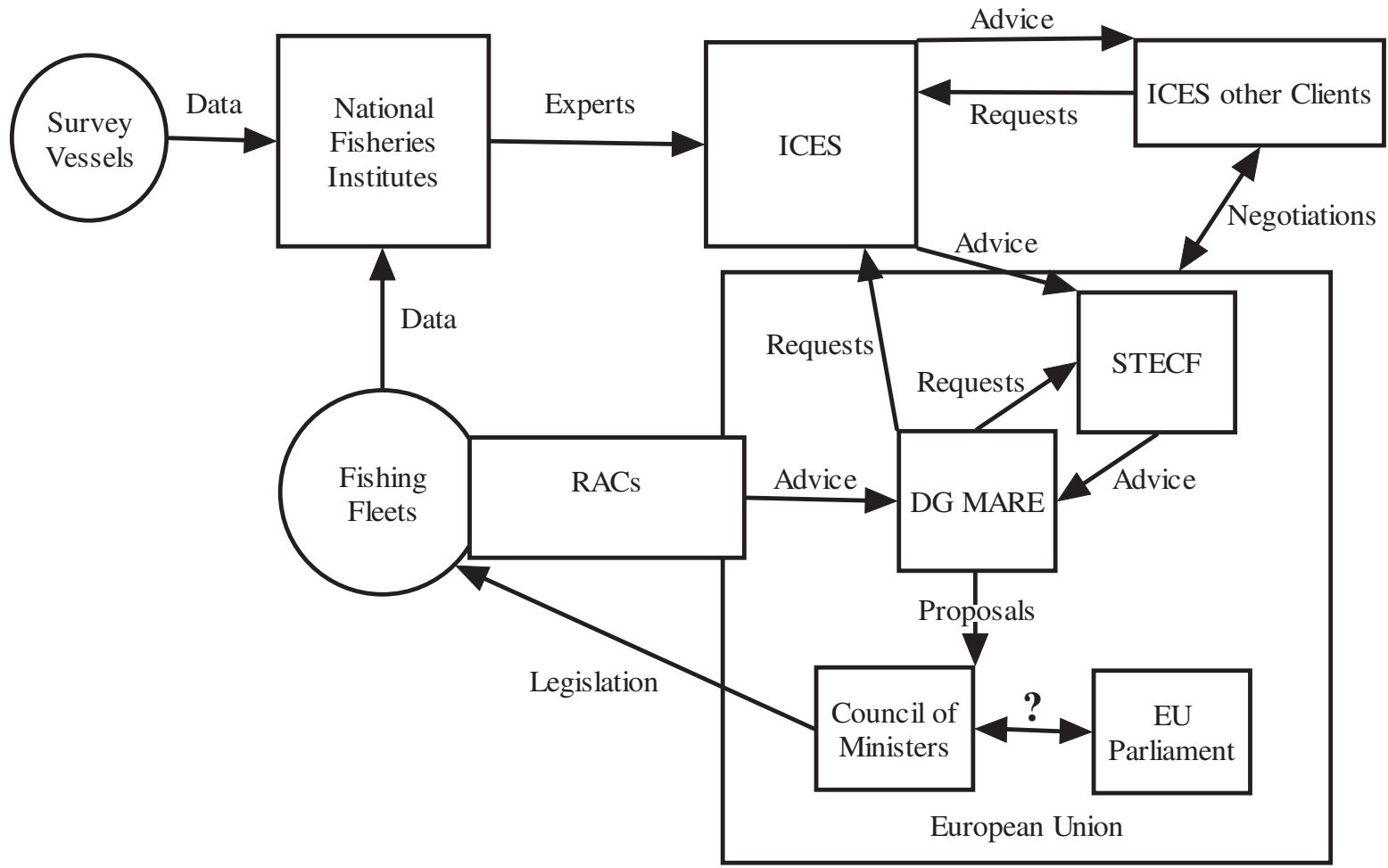

Fig. 1. Overview of the decision-making system for fisheries management in Europe (Wilson, 2009). Used by permission.

The figure outlines the decision-making system for the CFP. Fishing vessels and research survey vessels are the only parts of the system that actually touch the sea. They are symbolised by circles on the left side of the figure. Both types of vessels feed data into the fisheries laboratories of Member State governments. The laboratories supply their experts, armed with their country's data, to the International Council for the Exploration of the Sea (ICES), the intergovernmental organisation that produces the official fisheries science advice. In 2009 ICES was providing recurring advice for thirty-eight species and a much higher number of individual stocks.

The next section of the figure is the box marked European Union that contains a number of subsections. The central actor, although not the final decision-maker, is the Directorate-General for Marine Affairs and Fisheries (DG MARE). DG MARE directs funds and requests for advice to ICES. After ICES produces the official advice it must pass through the Scientific, Technical and Economic Committee for Fisheries (STECF) where it is reviewed and economic information added. STECF then passes it on to the policymakers in DG MARE. DG MARE also considers advice from the seven Regional Advisory Councils (RACs) comprised of different fisheries stakeholders. A RAC is required by the EU to allocate two thirds of its seats to the harvesting sector and one third to all other interest groups, of which the most active are the marine conservation ENGOs.

DG MARE proposes measures to the Council of Ministers. The decision-making power has recently been expanded to include a "co-decision" by the European Parliament. How that will work is still unclear. The Council of Ministers decides on the fisheries legislation on a yearby-year basis. While they issue a number of "technical measures", i.e. rules about how to catch fish and restrictions on how much fishing will be allowed, the most important decisions are related to setting the Total Allowable Catches (TAC) for each commercial fish stock and their associated Member State quotas. The quotas are governed by the relative-stability rule, under which quota allocation reflects an agreed balance between Member States. It is Member State governments that allocate their nation's quota among their fishers. Member States are also responsible for passing the relevant regulations as well as monitoring and enforcing compliance, but the EU role is growing rapidly in this area. The general recognition of the CFP's conservation failure led to the development of "recovery plans" that began as emergency measures but were quickly institutionalised. The first recovery plan in February 2001 was for the North Sea cod, which is fished in a classic MSMF shared by several countries, many fleets and several interacting species. 


\section{The ecosystem approach to fisheries management}

\section{The EAFM as it is generally understood}

Most experts agree that fisheries must be approached from an ecosystem perspective but there is little agreement on what that means in practice (Wilson, 2009). It is clear that it will result in a set of very complex commons as defined above. At a minimum, the EAFM calls management attention to both the implications of fishing for the broader environment, such as impacts on the sea bottom or damage to marine mammals, as well as impacts on fish stocks from non-fishing related causes. These things have historically been seen as outside the scope of fisheries management.

The most widely cited source for the EAFM in fisheries is a FAO Technical Paper (Garcia et al., 2003) in which the EAFM is defined as follows:

Q1. “The Reykjavik FAO Expert Consultation (FAO 2003) agreed that the 'purpose of an ecosystem approach to fisheries is to plan, develop and manage fisheries in a manner that addresses the multiplicity of societal needs and desires, without jeopardizing the options for future generations to benefit from a full range of goods and services provided by marine ecosystems'. Therefore, 'an ecosystem approach to fisheries strives to balance diverse societal objectives, by taking account of the knowledge and uncertainties about biotic, abiotic and human components of ecosystems and their interactions and applying an integrated approach to fisheries within ecologically meaningful boundaries.'" (Garcia et al., 2003, p. 6).

Here, the emphasis is on SES integration, knowledge and uncertainty, and spatial approaches. Garcia et al. (2003) further argue that the EAFM requires strong legislation with effective implementation and enforcement, and co-ordinated decision-making among agencies:

Q2. "Intersectoral planning and coordination must be improved, on an ecosystem basis, particularly when resources are shared (e.g. space shared among aquaculture, transportation and fisheries) or nuisances are transboundary. This requires developing collaboration between institutions in charge of the different economic sectors as well as of research, environment, etc. Such collaboration will not be very effective without explicit allocation of natural resources and space and improved coherence between sectoral legislative frameworks. A requirement in this respect is to improve coordination between regional fishery and environmental commissions." (Garcia et al., 2003, p. 37).

In addition, they continue, the overall governance requirements include (among other things):

Q3. "Decentralisation of decision-making and management responsibility to lower-than-central national level (e.g. to coastal communities), building the necessary capacity at that level [...] Higher participation of stakeholders in decision-making [...] Improved transparency, diffusing more information and installing oversight mechanisms." (Garcia et al., 2003, p. 39).

This presents a tension and a challenge. Strong legislation and a comprehensive, inter-agency decisionmaking do not fit easily with decentralisation and increased participation. Furthermore, ecosystems are tricky units of governance. Democracies need firm legal definitions and calculable rules to hold both industries and bureaucracies accountable. Ecosystems make this hard because they are difficult to understand or measure, let alone predict. Scientists need "clear objectives" if they are to evaluate management, but changing operational objectives is implicit in adaptive management in a democracy, so stated objectives vacillate between being either impractically narrow or so abstract as to give little guidance in particular situations (Wilson, 2009).

\section{Stakeholder views of EAFM in Europe}

Within European MSMF one area that most stakeholders do agree upon is that focusing on just the impacts of fishing on one stock is not adequate for conservation. Q4 comes from an interview with a RAC Member from an ENGO:

Q4. “What would you say are the most important lessons from past experience with recovery plans in Europe? Conservationist RAC Member: To use a single species approach, given our understanding of how species operate within an ecosystem context, is probably at best naive."

Q5 comes from a RAC Staff Member. He agrees that the single species approach is not advisable but a subtle difference can be seen in that his emphasis is on mixed fisheries, rather than the multi-species emphasis in Q4:

Q5. “Interviewer: When something has to be done about a depleted stock, is a recovery plan a good approach? RAC Staff Member: No, the big thing with recovery plans of course is, as you mentioned it, that the focus is on a particular species or stock... the problem with the cod recovery plan, that the Commission thought in terms of simply stopping fishing on cod without realising that that would actually jeopardize some fisheries on quite sustainable stocks."

Depleted stocks are under pressure from non-fishing sources such as climate change or seal predation. A real difference among stakeholders is how these factors should be treated under an EAFM. Other stakeholders are mainly concerned with the impacts from fishing on habitat and other fish predators, whereas fishers want an emphasis on the other sources of fish mortality, as such an emphasis suggests that overfishing is not as great a problem as it seems, and that an EAFM means seeking to reduce the impact of other predators on commercial fish stocks, for example by culling seals. Hence, there is inbuilt conflict about what the boundaries will be of the complex commons that an EAFM will construct. 


\section{Stakeholder perceptions of recovery plans in MSMF}

This section offers a brief account of the most contentious issues around recovery plans in MSMF in Europe. As much as possible it reflects the voices of stakeholders, most of whom are working through Regional Advisory Councils (RACs). As mentioned above, RACs are the main mechanism for stakeholder input into the CFP. For MSMF issues the two most important types of stakeholder are the fish harvesting industry and ENGOS. The first of the two parts of this section describes the basic political problem in MSMF management. The second outlines three areas of particular concern in developing legitimate management policies: regulatory discards; quotabased vs effort-based control of fishing mortality; and, problems with developing an adequate scientific basis for decision making.

\section{Species recovery in MSMF is a formidable political problem}

The basic problem for recovery in MSMF is a social and political one:

Q6. “Interviewer: You haven't actually been involved in anything to do with the cod recovery plan? Fisheries Scientist: No, thankfully. Interviewer: Why do you say that? Fisheries Scientist: Well, because it's so political. And the real problem with cod is that people are catching it when they're fishing for haddock or whiting. And they're catching the cod before it has had a chance to breed."

MSMF are "so political" as the scientist in Q6 puts it, because questions of fairness to different groups of fishers arise quickly. People's judgements about fairness are not related to some abstract ideal of what should be; it rather comes from comparing themselves to others they see as similar (Loomis and Ditton, 1993). MSMF provides many opportunities for such comparisons. One senior manager from the European Commission described the problem this way:

Q7. "When ICES advises a closure for cod, haddock and whiting and not for plaice, sole and nephrops there is a perception in the whitefish sector that the flatfish sector is not taking up its share of the conservation burden."

The fishing industry is often supportive of efforts to recover the depleted stockitself. The problem is that many of the most efficient fishing gears do not discriminate well among the species in a MSMF, so limits on fishing recovery species also limit fishing on other stocks. Indeed, as Q8 illustrates, the multi-stakeholder North Sea RAC takes a consensus position that the conservation of cod has had positive impacts on the conservation of other species. However, the quote also makes clear that while fishers are willing to cut back on catching depleted stocks, making it harder for them to catch their quotas of healthy stocks is not acceptable.
Q8. "Stocks such as haddock, sole, plaice, nephrops, saithe, monkfish and whiting are the principal mainstays of the fishing economy in the North Sea. Measures taken for cod recovery reasons appear to have had significant positive consequences for these stocks. The Review should address the question of how cod recovery measures can be effective for cod without resulting in adverse economic consequences for the non-cod fisheries." (NS RAC position on Cod Recovery Measures, 2006, p. 7).

Finding a fair and rational way to address this problem is one reason some stakeholders see an EAFM, where this problem could be addressed directly, as part of the solution to the MSMF problem.

Q9. "What is the main challenge for recovery plans in a mixed fisheries context? Conservationist RAC Member: Ideally, recovery plans should be incorporated into a strategic approach which looks at recovery of stocks within regional seas, or at larger scales if this is more appropriate. It appears that a requirement to protect/restore ecosystem functioning is missing from the current application, and this must be incorporated into process into the future, if recovery is to be successful [...] I am an advocate of the ecosystem approach - which I believe needs to be integrated into the recovery plans if they are to deliver. The plan should, if that's what the industry requires to be viable, have the option to switch between fisheries, provided that the overall take of all species and individual species is within the limits determined by scientific assessments."

While stakeholders do not agree on the boundaries of the emerging complex commons there is some agreement that they will have to allow more flexible fishing operations in response to ongoing ecological changes.

\section{Legitimacy and species recovery within an MSMF}

A desire for legitimacy pervades CFP institutions. On the one hand there is a need for cooperation and compliance from the fishing industry, on the other hand a growing interest in fisheries among environmental NGOs and labelling schemes has led to both legal and consumer pressure towards sustainable fisheries. MSMF are where legitimacy is the hardest to achieve because of the complexity of tightly linked issues and the number of stakeholders. In this section, three areas are presented where legitimacy is decreased by perverse outcomes from existing attempts to treat these issues as a problem of technical regulation.

\section{Regulatory discards: Throwing away dead fish}

When fishers argue that a recovery plan is not needed, they either claim that the stock was never a problem or that it has already recovered. The latter is much more common. Fishers associate a depleted stock with a lack of fish as such. If they see many fish from the plan stock they 
conclude that recovery is not needed. Managers, conservationists and scientists tend to define recovery not simply in terms of abundance but also in terms of the age structure of the stock. If a stock has recovered from depletion, then older and larger fish can be found in proportions that resemble what would be found in an unfished stock.

When a recovery plan is beginning to have an impact, the stock begins to recover in numbers, but the fish are still young. Because of the increased numbers of the recovery plan species, fishers are catching, and with mobile gear this means killing, more recovery plan fish while fishing for other species. They are not allowed to sell or even land these $\mathrm{fish}^{2}$. So they find themselves simultaneously a) seeing many fish, which shows that the recovery measures are not needed, and b) confronted with what may be the most legitimacy destroying outcome in fisheries management: "regulatory discards", i.e. the managers are making them throw perfectly good fish back in the water dead.

\section{Effort vs quota management: Dividing the fish}

The two basic approaches to fisheries management are: a) to control the amount and type of fishing activities or b) to control the amount of fish that can be taken. In Europe these two approaches are expressed respectively as effort management (including increasingly marine protected areas) and quota management. Both approaches have their strengths and weaknesses, but in MSMF the attraction of effort management is greatly enhanced.

The strength of quota management is that the fish can be allocated according to well-defined quantities. This makes it much easier to divide the fish, for example among countries or fishers, as in "enclosure" schemes such as Individual Transferable Quotas (ITQs). But quota management makes the science more challenging because it requires the calculation of a TAC. At the same time, it tends to bias the information used in these calculations by increasing incentives for discarding and illegal landings because under an effort system a vessel can keep and sell whatever it catches.

Science for effort management requires less precision - projecting how many fish will be in the sea next year is no longer needed - and does not involve the separate allocation of quotas for species in a MSMF. However, fishing effort is much more difficult to define and allocate than fish quotas. Common methods are limiting "days-at-sea" or a more complex form that considers vessel power lim-

2 Discard regulation is a very fluid arena now as Europe is moving quickly toward a general ban on discards. Such a ban will shift but not solve these problems. iting "kilowatt days-at-sea". The main difficulty is "effort creep", the continually improving ability of fishers to catch more fish per unit of time. The result of effort creep is that more fish are caught than was foreseen when the management plan was made.

A scientist explains the attraction of an effort system in a mixed fishery context:

Q10. “Interviewer: Doyou have an idea of what will work? Fisheries Scientist: An appropriate form of effort regulation. But practically implementing and getting people to agree what that should be is a huge political problem, I think. Interviewer: Why does it solve everything conceptually? Fisheries Scientist: Well, if you don't fish, you don't catch any fish, so there's no fishing mortality."

When the recovery plans were introduced effortbased measures were introduced as well. This was a very major change for much of the European fishing industry.

Q11. "RAC Staff Member: I think the cod recovery plan was probably the first one to come in, wasn't it? And with it went this concept of effort control, and in a way effort control was identified with the cod recovery plan because it had such far reaching implications for fishermen. So, it was really the effort control aspect of it that had most, received most debate within the RAC."

The critical problem of measuring effort quickly became evident:

Q12."Commission Administrator: The implementation of reform and recovery plans has been about moving from managing outputs to managing inputs... Effort is a very complex notion because so many different kinds of measurement and terminologies are used. A tonne is always a tonne, but a kilowatt is not always a kilowatt! [...] We are condemned to live with TACs and quotas because they are the measuring stick for allocations, and effort is less easy and transparent for finding an objective and verifiable indicator of allotment."

Allocating fish among Member States is of central importance in the CFP. Furthermore, the influence of economic theories about using transferable quotas as a mechanism for commons enclosure has grown. As a result the recovery plans did not shift the system from output control to input control, rather they created hybrid schemes using both effort and quota limitations. This hybrid has not proven very satisfactory:

Q13. "Member State Fisheries Manager: [...] One of the big challenges that we have now, that is to elaborate the system where we have TAC quotas, but also limit the fishing effort. I think that is important. I don't think my minister agrees with me. He is not very fond of days-at-sea [...] he actually agrees with the fishers, that it is not reasonable to have two management systems, quotas and days-at-sea, at the same time."

It is this hybrid management rather than the effort control as such that has created the most problems for the 
legitimacy of the recovery plans. The result here was serious problems in the political support for recovery plans even among Member State fisheries agencies. Burgeoning control measures developed to shore up earlier measures are a common problem in both the technical regulation and attempted enclosure of fisheries (Murray et al., 2010). Enclosure approaches, while simplifying management in some ways, have usually required complex auxiliary institutions to be implemented (Sanchirico et al., 2005).

\section{Overburdening uncertain science}

Using the "best available science" is the key means for demonstrating the legitimacy of the management decisions. When managers encounter legitimacy problems they often turn to scientists to find technical reasons to justify the decisions they see need to be made (Wilson, 2009).

For the MSMF two kinds of advice are needed beyond assessments of individual stocks. "Multi-species" advice describes how stocks interact, indicating other pressures on a stock beyond fishing. "Mixed fishery" advice describes how different fisheries catch different species, e.g. if a fleet is fishing for haddock how much cod will it catch? This is needed to determine the degree to which fisheries on other species should be limited to protect the recovery plan species. One problem is that, while seemingly clear from a layperson's perspective, from an analytic viewpoint a "fishery" is a fuzzy concept that involves boats of specific types using gears of specific types targeting a specific species, and which also may benefit from the "by-product" of valuable species they do not target. Mixed fishery advice is about fishing fleets rather than fish stocks, so fisheries scientists must build models based on units more appropriate to social science (Wilson and Delaney, 2005). Theoretically, one can produce advice for MSMF by modelling the relative effort and the catch compositions of the different fleets. Detailed information is needed on the catch for all species and fleets. The models are very sensitive to changes in fisher behaviour, including changes in response to these same management measures (Reeves, 2005).

An instructive interchange happened in 2003 as the need for advice for North Sea cod was reaching a peak (Wilson, 2009). ICES felt that they simply did not have enough accurate and well-organised data to offer either mixed species or mixed fisheries advice. The official advice produced by ICES read as follows:

Q14. “It is not currently possible to provide analytical forecasts for input into mixed fishery evaluation models. The main obstacle is that ICES does not have access to discard data for most fisheries. Development of such capability furthermore requires better catch monitoring, fishery analyses, and management decisions." (ICES, 2003, pp. 5-6).
ICES believed that the data was insufficient for forecasting the impacts of various combinations of fleet effort. This is understandable as the North Sea fisheries comprised, depending on their definition, approximately twenty relevant fleets and sixty sections of fleets with different gear and fishing patterns. ICES' final advice was that the cod could not withstand any fishing from any source. This response was not good enough. A DG MARE scientist describes the issue:

Q15. “ICES just said do not fish cod... would require closing the demersal fisheries [author's note: 'demersal' means fishing near the bottom where cod and many other species swim] [...] They gave us some defined biological limits but have refused to give forecasts for cod, haddock and some others. This is the advice I have received. What will you do, I ask you? No fishing is not an option! Scientists don't tell you the elements of a recovery plan, they don't guide you."

DG MARE gave the problem to STECF. STECF recognised the validity of ICES' position but also believed that "despite its numerous limitations, it would be more appropriate to provide advice based on evidence for the mixed-species nature of the different fisheries than advice that completely ignores the effects of technical interactions on the implementation success of TAC-based management" (STECF, 2003, p. 56). STECF agreed that the data problems would be fatal for mixed fishery advice, but not for multispecies advice.

These actions had a direct impact on scientific legitimacy in respect to the cod recovery plan. A story circulated in ICES that DG MARE employees had said that this outcome demonstrated that ICES should have been able to do the analysis in the first place. The ICES scientists were not at all pleased by this. One scientist got a laugh at an ICES meeting by suggesting that "DG MARE is better than ICES because they are able to do more work with less data" (Wilson, 2009).

These problems with building a scientifically legitimate approach to setting MSMF quotas are still very much with us in spite of considerable work on building more sophisticated multispecies and mixed fishery models. These models remain highly sensitive to the quality of input data and the definition of fleets and subfleets. Again the allocation problem, this time among fleets, has greatly increased the complexity of the decisions to be made. In this case it has placed a great deal of extra weight on very uncertain science.

\section{Discussion: Complexity and marine commons}

To discuss the CFP as a commons one must first be willing to entertain the idea that a commons model, rather than or in addition to the model of the technical regulation 
of an industry, is an appropriate way to conceive the problem. The regulatory model has been historically hampered by the fact that surveillance of fishers has been so difficult, but this is changing with the advent of inexpensive monitoring devices. Needing legitimacy to ensure compliance is no longer as strong an argument against top-down regulation as it used to be. However, other problems with the regulatory approach are evident from the discussion above: a) the difficult tension built into an ecosystem approach between the need for both centralised analysis and decision-making, and broader and more responsive stakeholder participation; $b$ ) the intensification of the political aspects of MSMF because of the prominence of issues of fairness; $c$ ) the piling up of regulations and hybrid management schemes; and d) technical regulation demanding more of science than it is able to deliver.

When the commons model has appealed to regulators it has most often been in the form of the argument that the tragedy of the commons requires some kind of enclosure. It is increasingly being responded to through such devices as ITQs. Such property rights do empower (some) commoners in specific ways and they have proven helpful in many fisheries (Hannesson, 2004). The enclosure model is attractive to regulators because, if it can be achieved, the commons aspect of the problem is resolved along with the need for any further empowerment of the commoners.

As Bromley (1991) points out, however, the kind of property right that makes economic sense is a function of the unit value of the resource and the costs of exclusion. In terrestrial ecosystems the costs of exclusion are usually low, so common property appears where the unit value of the resource is also low. In aquatic ecosystems the costs of exclusion are high so valuable resources are also found as common property resources. Attempts to mimic terrestrial property rights cannot avoid dealing with the high costs of exclusion, i.e. finding a practical way to enforce a division of the fish. Considerable costs are involved here, both the costs of the ongoing scientific monitoring and analysis needed for establishing a TAC and the costs of enforcing the quotas once established. When ITQs have worked best, it has tended to be in fisheries where treating a single fish stock as a simple commons is the most feasible; otherwise complex and constantly shifting support institutions have been required (Sanchirico et al., 2005).

This problem of division pervades marine management beyond the enclosure problem. Effort management is a simpler approach to MSMF. Yet the difficulty of using effort as a metric of division is a political problem that blocks its use entirely or leads to the added burdens of hybrid systems. Quotas are constructed by ignoring the impacts of scientific uncertainty, which in turn leads to distortions in the scientific discussions, as in the examples given in the section on overburdened science above. Effort systems avoid the need for separate species quotas and require less precise science. The benefits of effort control are behind the growing popularity of marine protected areas, which are really blanket effort control systems, as simple and sometimes effective fisheries management devices (Degnbol et al., 2006). Furthermore, the division problem extends beyond quotas to the definition of fleets and subfleets where the regulatory bureaucracies force fishing vessels into ever smaller categories and make it hard to shift to other gear and species when needed (Wilson and Jacobsen, 2009). The mixed fishery experience suggests that the even more complex problems of the EAFM may also benefit from a strategy based more on reducing pressure than dividing resources.

Hence, the MSMF problem is a good example of how as a SES becomes more complex, a common property approach becomes more relevant. At least for marine commons in developed countries, more effective solutions in complex SESs seem to benefit from relying less on attempts to permanently define the boundaries or resources. Any approach to commons requires boundary creation of some type (Ostrom, 1990) but within marine ecosystems the definition of boundaries must be flexible and highly sensitive to local conditions. Dealing with these shifting boundary problems will need to take place within a basic common property approach through negotiations among empowered commoners.

In conclusion, moving away from a reliance on hard divisions would require greater use of our knowledge of common property management. Increasingly complex commons are emerging as the extent of the SES being placed under integrated forms of governance grows. Indeed, if the quotes found here are any indication, stakeholders of different types see the EAFM, with all its greater complexity, as part of the solution to the MSMF problems because the objects of decision-making become more realistic. Common property approaches will be increasingly considered because an ecosystem approach must deal with many areas where the division of goods and the rigid classification of activities and people will be difficult or even self-defeating.

\section{Acknowledgement}

Financial support for the research reported on here was provided under Contract No. 022717 to the UNCOVER project by the European Commission in the FP6 research programme. This work does not reflect the Commission's views and in no way anticipates its future policy in this area.

\section{References}

Bromley, D., 1991. Environment and Economy: Property Rights and Public Policy, Oxford, Basil Blackwell. 
CEC (Commission of the European Community), 2008. Directive 2008/56/Ec of the European Parliament and of the Council of 17 June 2008 Establishing a Framework for Community Action in the Field of Marine Environmental Policy (Marine Strategy Framework Directive), Brussels, DG Environment.

CEC (Commission of the European Community), 2009. Green Paper: Reform of the Common Fisheries Policy, Brussels, DG MARE.

Degnbol, P., Gislason, H., Hanna, S., Jentoft, S., Raakjær Nielsen, J., Sverdrup-Jensen, S., Wilson, D.C., 2006. Painting the floor with a hammer, Marine Policy, 30, 534543.

Froese, R., 2011. Fishery reform slips through the Net, Nature, 475,7 .

Garcia, S.M., Zerbi, A., Aliaume, C., Do Chi, T., Lasserre, G., 2003. The ecosystem approach to fisheries. Issues, terminology, principles, institutional foundations, implementation and outlook, FAO Fisheries Technical Paper, 443, Rome, FAO.

Hannesson, R., 2004. The Privatization of the Oceans, Cambridge (Mass.), The MIT Press.

ICES, 2003. ACFM Annual Report, Copenhagen, Denmark.

Loomis, D.K., Ditton, R.B., 1993. Distributive justice in fisheries management, Fisheries, 18, 2, 14-18.

McCay, B.J., Acheson, J.M. (Eds), 1987. The Question of the Commons: The Culture and Ecology of Communal Resources, Tuscon (AZ), the University of Arizona Press.

Murray, G., Johnson, T., McCay, B.J., Danko, M., St. Martin, K., Takahashi, S., 2010. Creeping enclosure, cumulative effects and the marine commons, International Journal of the Commons, 4, 1, 367-389.
NSRAC, 2006. North Sea RAC Position Paper on the Review of Cod Recovery Measures, Edinburgh, North Sea Regional Advisory Council (http:/ / www.nsrac.org/).

Ostrom, E., 1990. Governing the Commons, New York, Cambridge University Press.

Reeves, S., 2005. Mixed Fisheries. Paper presented at the European Fisheries Advisory System Evaluation meeting of The European Fisheries and Aquaculture Research Organisation, Gdynia, 21-22 October 2005.

Sanchirico, J.N., Holland, D., Quigley, K., Fina, M., 2005. Catch-quota balancing in multi-species individual fishing quotas, Resources for the future, Discussion Paper, 05-54.

Short, C., 2008. The traditional commons of England and Wales in the twenty-first century: Meeting new and old challenges, International Journal of the Commons, 2, 2, 192 221.

STECF, 2003. Scientific, Technical, and Economic Committee for Fisheries, Plenary Report \#17, Brussels, European Commission.

Wilson, D.C., Delaney, A.E., 2005. Scientific knowledge and participation in the management of fisheries in the North Sea, in Gray, T.S. (Ed), Participation in Fisheries Governance, Dordrecht, Springer.

Wilson, D.C., 2009. The Paradoxes of Transparency: Science and the Ecosystem Approach to Fisheries Management in Europe, Amsterdam, Amsterdam University Press.

Wilson, D.C., Jacobsen, R.B., 2009. Governance Issues in MixedFisheries Management: An Analysis of Stakeholder Views, Deliverable 6.3 for a framework for fleet and area based fisheries management (AFRAME) Project. EU Sixth Framework Programme, Contract no.: 044168.

Received the $6^{\text {th }}$ January 2011. Accepted the $2^{\text {nd }}$ February 2012. 